\title{
ANALISIS PERCEPATAN DURASI TERHADAP PEKERJAAN PROYEK KONSTRUKSI TIME COST TRADE OFF METHOD ( STUDI KASUS : PEMBANGUNAN GEDUNG DINAS PERDAGANGAN DAN PERINDUSTRIAN KABUPATEN SAMPANG )
}

\author{
Dedy Asmaroni ${ }^{1}$ and Ach Fendi ${ }^{2}$ \\ ${ }^{1}$ Teknik Sipil, Fakultas Teknik, Universitas Madura, Pamekasan \\ ${ }^{2}$ Teknik Sipil, Fakultas Teknik, Universitas Madura, Pamekasan \\ E-mail: dedyasmaroni@gmail.com,Ferefendy319@yahoo.com.
}

\begin{abstract}
ABSTRAK: Dalam pembangunan gedung dimana suatu konstruksi pekerjaan suatu proyek terdapat berbagai hal yang terjadi seperti, bertambahnya waktu dan kerusakan alat sehingga pelaksanaan akan mengakibatkan keterlambatan sehingga membutuhkan suatu perencanaan, penjadwalan serta pengendalian yang baik. Perencanaan dan penjadwalan yang kurang baik akan berdampak pada pekerjaan dan pelaksanaan konstruksi. Oleh karena itu, bisa dilakukan percepatan proyek konstruksi agar permasalahan yang ada bisa teratasi sesuai proses diharapkan. Metode yang digunakan pada penelitian ini merupaka metode deskriptif dengan jenis penelitian studi kasus. Penelitian studi kasus adalah penelitian suatu kasus studi atau subyek, tujuan dari studi kasus ini memberikan gambaran secara detail mengenai latar belakang dan sifat serta karakteristik khas dari suatu kasus studi sehingga dapat memahami objek yang ditelitinya. Hasil penelitian yang telah dilakukan menunjukkan dari hasil penjadwalan ulang pembangunan gedung kantor Dinas Perdagangan dan Perindustrian dengan menerapkan metode TCTO (Time Cost Trade Off) didapat waktu penyelesaian akibat percepatan adalah 133 hari dari durasi penyelesaian sebesar 150 hari jadi diperlukan percepatan 17 hari agar proyek dapat selesai sesuai target rencana. Adapun biaya total akibat dilakukan percepatan sebesar Rp. 1.256.929.349 dari biaya sebelumnya Rp. 1.227.823.795 terjadi penambahan biaya sebesar Rp. 29.105.553 sehingga didapat $2,37 \%$ kenaikan anggaran.
\end{abstract}

Kata kunci: Percepatan Durasi, Pekerjaan Proyek Konstruksi, Time Cost Trade Off.

\section{Pendahuluan}

Dengan seiringnya perkembangan ilmu pengetahuan diera globalisai dan kemajuan zaman, baik dari segi teknologi maupun perkembangan tentu akan di sertai peningkatan kebutuhan manusia dalam berbagai aspek kehidupan dimana adanya perkemabangan akan ada pertambahan kebutuhan serta bertambahnya pendudukdi kawasan Kabupaten Sampang, dimana itu berdampak pada perdagangandan perindustrian sehingga mengalami kesulitan dimana kebutuhan semakin meningkat. Peningkatan pada perdagangan dan perindustrian tersebut menyebabkan kesulitan dalam hal melayani dengan peralatan yang kurang memadai oleh karena itu adanya peralatan dan tempat serta alat untuk memenuhi kebutuhan masyarakat. Maka dari itu peningkatan dalam pelaksanaan pelayanan sangat penting bagi kebutuhan masyarakat agar bisa terpenuhi. .

Suatu pembagunan gedung konstruksi untuk menyediakan tempat yang lebih baik untuk masyarakat. Dalam pembangunan gedung dimana suatu konstruksi pekerjaan suatu proyek terdapat berbagai hal yang terjadi seperti, bertambahnya waktu dan kerusakan alat sehingga pelaksanaan akan mengakibatkan keterlambatan oleh karena itu membutuhkan suatu perencanaan, penjadwalan serta pengendalian yang baik. Perencanaan dan penjadwalan yang kurang baik akan berdampak pada pekerjaan dan pelaksanaan kontruksi. Hal tersebut dipengaruhi oleh kualitas dan ketersedianbahan material, serta lokasi pembangunan proyek.

Seperti pada proyek pembangunan gedung Dinas Perdagangan dan Perindustrian Kabupaten Sampang, dimana pada proyek tersebut tempat yang biasa digunakan untuk meletakkan material kontruksi sekarang digunakan untuk tempat parkir kendaraan para pegawai karena sepeda motor hingga menduduki bahu jalan karena karena keterbatasan lahan. Para pegawai juga merasa kesulitan dalam bekerja karena kekurangan tempat dan peralatan dalam jangka waktu pembangunan gedung Dinas Perdagangan dan Perindustrian Kabupaten Sampang dimana masyarakat mengalami antrian dan lamanya proses.

Oleh karena itu bisa dilakukan percepatan proyek kontruksi agar permasalahn yang ada bisa teratasi sesuai proses diharapkan. Hal ini yang akan di amati untuk memenuhi penelitian skripsi yang berjudul "Analisis Percepatan Durasi Terhadap Pekerjaan Proyek Konstruksi Time Cost Trade Off Methodestudi kasus Pembangunan Gedung Dinas Perdagangan dan Perindustrian Kabupaten Sampang" agar didapat durasi waktu yang optimal dan tepat.

\section{Lokasi Penelitian}

Kantor Dinas Perdagangan dan Perisdustrian Kabupaten Sampang. Studi kasus pada penelitian kali ini dilakukan pada proyek pembangunan kontruksi Dinas Perdagangan dan Perindustrian Kabupaten Sampang yang berlokasi di Jln.Diponegoro No.52A kecamatan sampang kabupaten sampang 2017. Dapat di lihat pada Gambar 1 peta dibawah ini. 


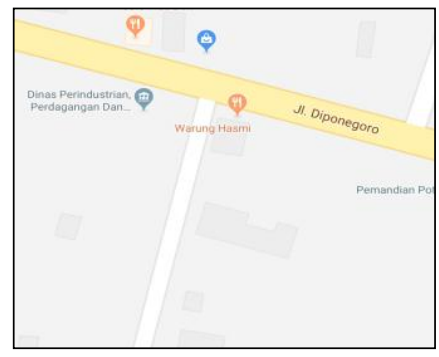

Gambar.1. Peta Lokasi Pembangunan Gedung Proyek

\section{Metode penelitian}

Metode yang digunakan pada penelitian ini merupakan metode diskriptif dengan jenis penelitian studi kasus. Penelitian studi kasus adalahpenelitian suatu kasus studi atau subyek, tujuan dari studi kasus ini memberikan gambaran secara detail mengenai latar belakang dan sifat serta karakteristik khas dari suatu kasus studi sehingga dapat memahami objek yang ditelitinya.

\section{Jenis Data}

Ada dua jenis data yang dapat di gunakan dalam penelitian ini yaitu :

\section{1) Data Primer}

Data primer adalah data yang diperoleh langsung dari subyek maupun sumber asli, data primer ini berupa data wawancara dengan pihak-pihak yang terkait dalam pelaksanaan proyek kontruksi mengenai biaya dan komponen serta yang lainnya.

a. Kurva $S$

Kurva $S$ merupakan data yang digunkan sebagai data variabel waktu penyelesaian proyek. Kurva $\mathrm{S}$ diperlukan untuk menegetahui waktu dan durasi terhadap masing-masing pekerjaan, selain itu juga dapat digunakan sebagai acuan durasi waktu normal proyek.

b. Rencana Anggaran Biaya ( RAB )

Rencana anggaran biaya ( RAB ) merupakan data-data pekerjaan serta biaya yang dibutuhkan sebagai variabel sebagai acuan biaya nomal.

c. Daftar harga satuan upah yang digunakan oleh konsultan perencana adalah harga pemerintah.

\subsubsection{Data skunder}

Data sekunder adalah data yang diperoleh dari pihak lain atau secara tidak langsung, dan data yang sudah tersedia sehingga hanya perlu dicari, dikumpulkan dan diolah yang diperoleh dari intansi terkait.

a. Laporan Mingguan

Laporan harian ialah laporan yang dibuat oleh pelaksana lapangan untuk mengetahui ke adaan dan kondisi manajemen proyek.

b. Laporan Bulanan

Laporan yang dibuat oleh pelaksana lapangan dari laporan mingguan untuk dijadikan laporan bulanan.

\subsection{Prosedur Penelitian}

Prosedur penelitian adalah suatu penelitian harus dilakukan sistematis dengan urutan yang jelas dan teretur, sehingga akan di peroleh suatu hasil dengan yang di harapkan. Oleh sebab itu, pelaksanaan penelitian ini dibagi dalam beberapa tahap-tahap sebagai berikut :

\section{Tahap I : Pesiapan Pendahuluan}

Pada tahap Persiapan ini merupakan pendahuluan sebelum melakukan suatu penelitian adapun persiapan-persiapan alat serta yang lainnya.

Tahap II : penentuan obyek penelitian

Diman pada tahap ini adalah untuk menentuakan lokasi letak proyek yang akan dilakukan penelitian sehingga dapat mengetahui lokasi proyek tersebut.

Tahap III : pengumpulan data

Merupakan langkah-langkah yang dilakukan, mengumpulkan data sekunder maupun primer yang akan dijadikan sebagai obyek penelitian dari konsultan perencana data-data meliputi sebagai berikut :

1. Rencana anggaran biaya ( RAB ).

2. Analisis harga satuan pekerjaan.

3. Kurva $\mathrm{S}$.

4. Daftar harga satuan upah

Tahap IV : Analisis data

Menganalisis data normal duration dan normal cost keduanya diperoleh dari pengumpulan data. Pelaksanaan suatu percepatan durasi dilakukan pada kondisi normal dan percepatan untuk menghindari denda dengan menggunakan penambahan jam kerja lembur.

Dari uraian di atas dapat ditulis sebagai berikut ini:

1. Produktivitas harian $=$ Volume durasi normal

2. Produktivitas tiap jam $=$ Produktivitas harian jam kerja perhari.

3. Produktivitas harian sesudah $c r a s h=($ Jam kerja perhari $\times$ Produktivitas tiap jam $)+(\mathrm{a} \times \mathrm{b} \times$ Produktivitas tiap jam ).

Dengan: $\mathrm{a}=$ lama penambahan jam kerja (lembur).

$\mathrm{b}=$ koefisien penurunan produktivitas akibat penambahan jam kerja (lembur ).

Dari uraian di atas dapat ditulis sebagai berikut ini:

1. Produktivitas harian $=$ Volume durasi normal .

2. Produktivitas tiap jam $=$ Produktivitas harian jam kerja perhari.

3. Produktivitas harian sesudah crash $=(\mathrm{Jam}$ kerja perhari $\times$ Produktivitas tiap jam $)+(a$ $\times \mathrm{b} \times$ Produktivita tiap jam).

Dengan: $\mathrm{a}=$ lama penambahan jam kerja (lembur)

$\mathrm{b}=$ koefisien penurunan produktivitas akibat penambahan jam kerja (lembur).

4. Crash duration $=$ Volume produktivitas harian sesudah Crash

Tabel2.2. Nilai koefisien penurunan produktivitas

\begin{tabular}{|c|c|c|}
\hline Jam lembur & $\begin{array}{c}\text { Penurunan } \\
\text { Indeks } \\
\text { produktivitas }\end{array}$ & $\begin{array}{c}\text { Prestasi } \\
\text { Kerja }\end{array}$ \\
\hline 1 jam & 0.1 & 90 \\
\hline 2 jam & 0.2 & 80 \\
\hline 3 jam & 0.3 & 70 \\
\hline 4 jam & 0.4 & 60 \\
\hline
\end{tabular}

Perhitungan untuk penambahan tenaga kerja dirumuskan sebagai berikut ini :

1. Jumlah tenaga kerja normal $=($ Koefisien tenaga kerja $x$ Volume $)$..........Pers. 1 
Durasi waktu

2. Jumlah tenaga kerja dipercepat

$=($ Koefesien tenaga kerja $\times$ volume $)$........Pers. 2

Durasi dipercepat

Dari rumus di atas maka akan diketahui jumlah pekerja normal dan jumlah penambahan tenaga kerja akibat percepatan durasi proyek.

Perhitungan untuk biaya tambahan pekerja dapat dirumuskan sebagai berikut ini:

3. Normal ongkos pekerja perhari

$=$ Produktivitas harian $\times$ Harga satuan upah pekerja......................................Pers. 3

4. Normal ongkos pekerja perjam

$=$ Produktivitas perjam $\times$ Harga satuan upah pekerja...................................................Pers. 4

5. Biaya lembur pekerja

$=1,5 \times$ upah sejam normal untuk penambahan jam kerja (lembur) pertama $+2 \times n \times$ upah sejam normal untuk penambahan jam kerja

(lembur) berikutnya... Pers. 5

Dengan: $\mathrm{n}=$ jumlah penambahan jam kerja (lembur)

6.Crash Cost pekerja perhari

$=($ Jam kerja perhari $\times$ Normal cost pekerja $)+$

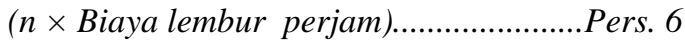

7. Costslope

$=\underline{\text { Cras Cost }- \text { Normal Cost }}$

..Pers. 7

Durasi Normal - Durasi Cras

4. Crash duration $=$ Volume produktivitas harian sesudah Crash

Tahap V : pembahasan

Dari data-data yang sudah diolah agar menghasilakan data yang di butuhkan dalam penelitian yang akan dibahas untuk menentukan perbandingan biaya awal sampai percepatan dilakukan.

Tahap VI : Kesimpulan dan Saran

Rangkuman dari permasalahan yang terjadi pada pembangunan yang suadah dilakukan percepatan dan menghasilkan perbandingan biaya-biaya yang terjadi.

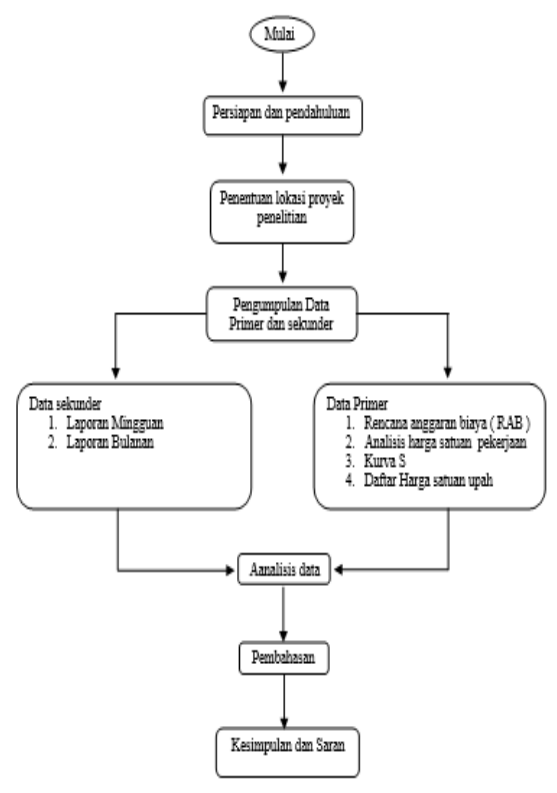

ANALISA DAN PEMBAHASAN

\section{Menyusun Analisa}

1) Identifikasi aktivitas (kegiatan)

Identifikasi aktivitas (kegiatan) sisa dilakukan hanya sampai pekerjaan struktur selesai, yaitu sampai pengerjaan lantai atap. Identifikasi ini kita tinjau mulai minggu ke 1 hingga minggu ke 20 prestasi struktur yang harus dicapai $100 \%$.

\section{2) Perhitunan produktivitas harian normal}

Setelah aktivitas (kegiatan) sisa proyek didapatkan, maka langkah selanjutnya menentukan hubungan keterkaitan antar aktivitas (predecessor dan successor) berdasarkan urutan pekerjaan dilapangan. Hubungan antar aktivitas ini disesuaikan dengan kapan aktivitas ini harus dimulai dan kapan harus selesai. Hubungan antar aktivitas diperoleh dari jadwal yang terdapat dilapangan, yang kemudian dibreakdown menjadi sub-sub pekerjaan.

\section{3) Hubungan keterkaitan antar aktivitas ( kegiatan )}

Setelah durasi proyek didapatkan, maka langkah selanjutnya menentukan hubungan keterkaitan antar aktivitas (predecessor dan successor) berdasarkan urutan pekerjaan dilapangan. Hubungan antar aktivitas (kegiatan) ini disesuaikan dengan kapan aktivitas (kegiatan) ini harus dimulai dan kapan harus selesai.

\section{Analisa Time Cost Trade Off \\ 1) Membuat Network diagram dan menghitung normal Duration}

Setelah mengetahui hubungan antar aktivitas (kegiata) (predecessor dan successor) dan kita telah menghitung durasi dari masing-masing aktivitas (kegiatan) berdasarkan produktivitas normal, maka langkah selanjutnya adalah membuat jaringan kerja (network planning).

Dalam menyusun hubungan antar aktivitas (kegiatan) maupun kapan suatu aktivitas (kegiatan) dilapangan dimulai dan kapan harus selesai. Setelah itu untuk menyusunnya kami menggunakan bantuan program Microsoft Project.

Kemudian dari jaringan kerja yang telah selesai dapat kita lihat normal duration, yaitu total durasi yang dibutuhkan untuk menyelesaikan aktivitas sisa yang ada.

\section{2) Menghitung Normal Cost}

Produktivitas harian percepatan diperoleh dari jumlah produktivitas harian normal dengan produktivitas pekerjaan saat jam lembur per hari. Penambahan jam kerja lembur sesuai peraturan yang berlaku dilakukan selama 3 jam per hari, sedangkan produktivitas pekerja jam lembur diasumsikan mengalami penurunan, dan hanya diperhitungkan sebesar $80 \%$ dari produktivitas jam kerja regular.

percepatan pekerjaan kritis adalah sebagai berikut :
a. Menghitung volume pekerjaan
b. Menghitung durasi normal
c. Menghitung produktivitas harian normal
d. Produktivitas normal/jam
e. Produktivitas jam lembur
f. Produktivitas harian percepatan 
Perhitungan produktivitas harian normal pada Pengukuran \& Bowplank:
a. Volume pekerjaan
$=86,1 \mathrm{~m}$
$\begin{array}{ll}\text { b. } \text { Harga Satuan } & =\text { Rp. } 63.790,96 / \mathrm{m} \text { ' } \\ \text { c. } \text { Normal cost } & =\text { Rp 5.492.401,656 } \\ \text { d. } \text { Durasi normal } & =8 \text { hari }\end{array}$
e. Produktivitas harian normal $=\mathrm{a} / \mathrm{d}$

$=\frac{86.1 \mathrm{~m} t}{8 \text { hari }}=10.763 \mathrm{~m}$ ' /hari

f. Produktivitas normal/jam $=\mathrm{e} / 8$

$=\frac{10.763 \mathrm{~m}^{J} / \text { hari }}{8 \mathrm{jam} / \mathrm{hari}}=1,345 \mathrm{~m}^{\prime} / \mathrm{jam}$

g. Produktivitas Lembur $/ \mathrm{Jam}=3 \times \mathrm{f}$ x 0,80 $=3 \times 1,345 \times 0,80$ $=3,229 \mathrm{~m} / \mathrm{jam}$

h. Produktivitas harian percepatan $=(\mathrm{f}+\mathrm{g}) \times 8$ $=(1,345+3,229) \times 8$ $=36,593 \mathrm{~m}$ ' / hari

Dengan cara yang sama perhitungan produktivitas harian, normal dan percepatan di gambarkan pada tabel 4.1 .

Tabel 4.1. Produktivitas harian percepatan

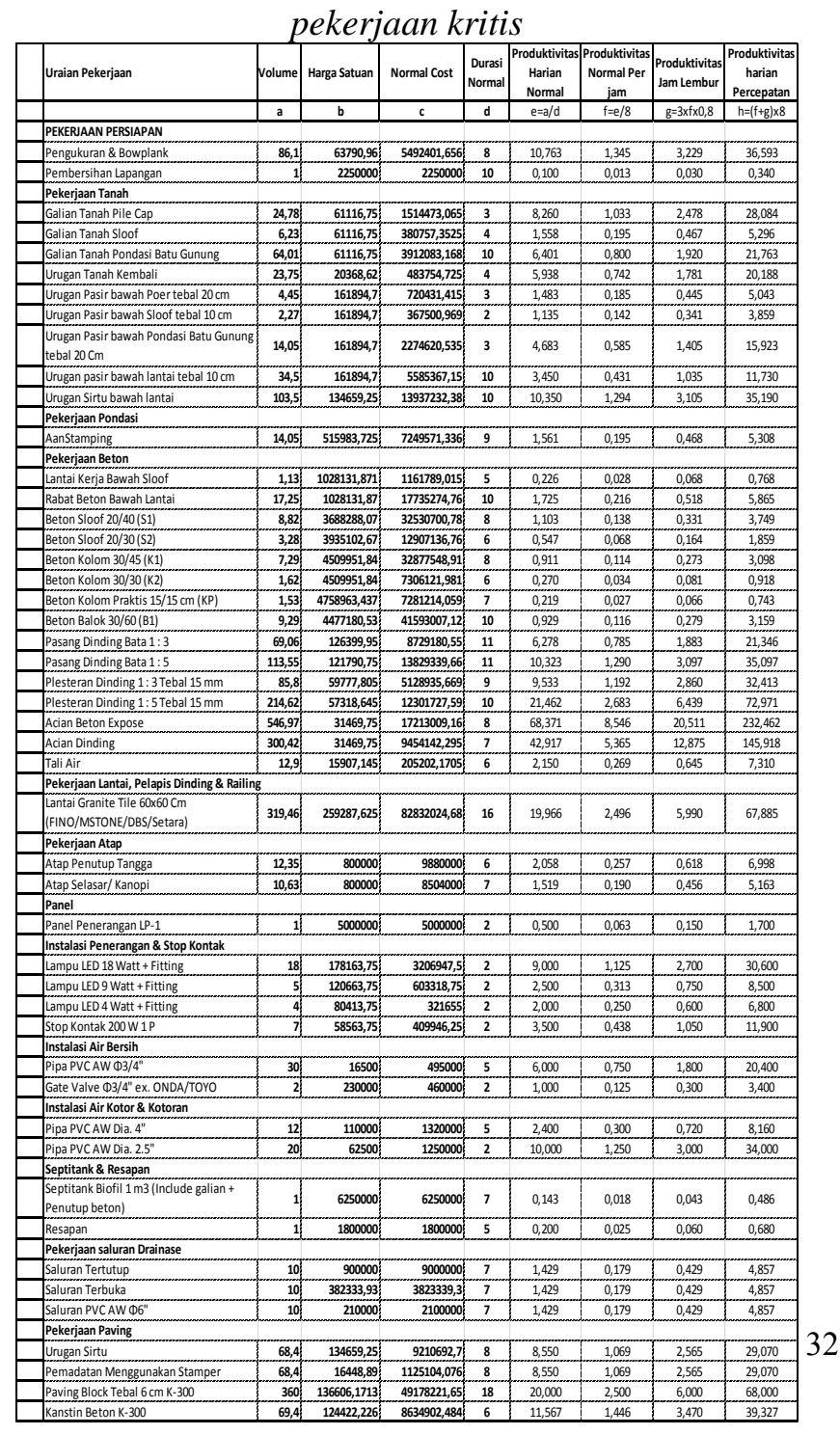

\subsection{Perhitungan Crash Duration, Crash Cost, danCost Slope}

Setelah diketahui besarnya produktivitas (kegiatan) harian percepatan pekerjaan kritis, maka langkah selanjutnya adalah menghitung durasi percepatan (crash duration) dan biaya langsung percepatan (crash cost). Perhitungan crash duration ini digunakan untuk mendapatkan batasan waktumaksimal suatu aktivitas

mampu untuk dilakukan crashing (crashability), sedangkan perhitungan crash cost digunakan untuk mencari slope biaya (cost slope) masing-masing aktivitas (kegiatan).

Untuk menentukan Crash Cost dapat dilakukan dengan langkah-langkah berikut:

a. Menghitung upah kerja harian normal, yaitu produktivitas harian $\mathrm{x}$ harga satuan upah kerja

b. Menghitung upah kerja normal, yaitu produktivitas per jam x harga satuan upah kerja

c. Menghitung upah kerja lembur per hari:

1. Untuk 3 jam lembur $=(1,5 \mathrm{x}$ upah jam normal $)+2(2 x$ upah jam normal $)$

2. Untuk 4 jam lembur $=(1,5 \mathrm{x}$ upah jam normal $)+3(2 \times$ upah jam normal $)$

d. Menghitung Crash Cost per hari, yaitu upahharian + upah kerja lembur per hari

e. Menghitung Crash Cost total, yaitu CrashCost per hari + Crash Duration

Perhitungan crash duration, crash cost, dan cost slope untuk Pekerjaan Lapis Permukaan Agregat sebagai berikut:

a. Volume pekerjaan $=86,1 \mathrm{~m}$

b. Durasi Normal $=8$ Hari

c. Normal cost $=$ Rp 5.492.401,656

d. Harga satuan = Rp. 63.790,96/ m

e. Produktivitas normal $/$ hari $=10,763 \mathrm{~m} / \mathrm{jam}$

f. Produktivitas normal $/ \mathrm{jam}=1,345 \mathrm{~m} / \mathrm{jam}$

g. Produktivitas Lembur $/ \mathrm{Jam}=3,229 \mathrm{~m} / \mathrm{jam}$

h. Produktivitas harian percepatan $=36,593 \mathrm{~m} / \mathrm{hari}$

i. Crash duration

$$
\begin{aligned}
& =\mathrm{b}-\frac{\mathrm{a}}{\mathrm{h}} / 8 \\
& =8-\left(\frac{86.1 \mathrm{~m}^{\prime}}{836,593 \mathrm{~m}^{\prime} / \text { hari }} / 8\right)=7 \text { hari }
\end{aligned}
$$

j. Upah normal/jam $=\mathrm{d} \times \mathrm{f}$

$$
\begin{aligned}
\mathrm{k} . \text { Upah normal/hari } & =\mathrm{j} \times 8 \\
& =\operatorname{Rp} 85.818,78 / \mathrm{jam} \times 8 \\
& =\operatorname{Rp} 686.550,207 / \text { hari }
\end{aligned}
$$$$
=\operatorname{Rp} 63.790,96 / \mathrm{m} \times 1,345
$$$$
\mathrm{m} / \mathrm{jam}
$$$$
=\operatorname{Rp} 85.818,78 / \mathrm{jam}
$$

1. Upah 3 jam lembur/ hari $=(1,5 \times \mathrm{j})+2 \times(2 \times \mathrm{j})$

$=(1,5 \times \operatorname{Rp} 85.818,78)+2 \times(2 \times \operatorname{Rp} 85.818,78)$

$=\operatorname{Rp} 472.003,267 /$ hari

m. Cost Upah Percepatan/hari $=(\mathrm{c}+1) / \mathrm{i}$

$=($ Rp. 5.492.401,656 + Rp. 472.003,267) $/ 7$

$=$ Rp.852.057,846/hari

n. Cost upah $=(\mathrm{c}+\mathrm{m})$

$$
=\mathrm{Rp} 5.492 .401,656 / \text { hari }+\mathrm{Rp}
$$


Jurnal Rekayasa Tenik Sipil Universitas Madura Vol. 4 No.2 Desember 2019 ISSN 2527-5542

o. Cost bahan = a x e

$=\operatorname{Rp} 6.344 .459,50 /$ hari

$$
\begin{aligned}
& =86,1 \text { m' x Rp } 0,00 / \mathrm{m}^{\prime} \\
& =\operatorname{Rp} 0,00 \\
& =86,1 \text { m' x Rp 0,00/m' } \\
& =\operatorname{Rp} 0,00 \\
& =\operatorname{Rp} 6.344 .459,50+\operatorname{Rp} 0,00+\operatorname{Rp} 0,00 \\
& =\operatorname{Rp} 6.344 .459,50
\end{aligned}
$$

\section{r. Cost slope}

$$
\begin{aligned}
& =\frac{\mathrm{q}-\mathrm{c}}{\mathrm{b}-\mathrm{i}} \\
& =\frac{\text { Rp. } 6.344 .459,50-\text { Rp. } 5.492 .401,656}{8 \text { hari }-7 \text { hari }} \\
& =\text { Rp. } 852.057,85
\end{aligned}
$$

\subsection{Perhitungan Selisih Waktu Dan Biaya Durasi Waktu Nomal Dan DurasiWaktu Dipercepat}

Dengan bantuan program bantu Microsoft. Project, dilakukan analisa pertukaran waktu dan biaya dengan melakukan kompresi atau percepatan pada lintasan kritis sampai diperoleh durasi dan biaya proyek setelah dipercepat.

\begin{tabular}{|c|c|c|c|c|c|c|c|}
\hline & Uraian Pekerjaan & Volume & $\begin{array}{r}\text { Durasi } \\
\text { Normal } \\
\end{array}$ & Harga Satuan & Normal Cost & \begin{tabular}{|c} 
Durasi \\
Percepatan \\
\end{tabular} & $\begin{array}{c}\text { Cost } \\
\text { Percepatan } \\
\end{array}$ \\
\hline & & $\mathrm{a}$ & $b$ & c & d & $\mathrm{e}$ & $f$ \\
\hline $1 \mathrm{P}$ & PEKERIAAN PERSIAPAN & & & & & & \\
\hline$A$ & PEKERIAAN PERSIAPAN & & & & & & \\
\hline 1 & Pengukuran \& Bowplank & 86,10 & 8 & $63.790,96$ & $5.492 .401,66$ & 7 & $5.964 .404,9$ \\
\hline \multirow[t]{2}{*}{2} & Pembersihan Lapangan & 1,00 & 10 & $2.250 .000,00$ & $2.250 .000,00$ & 9 & $2.404 .687,5$ \\
\hline & & & & & $7.742 .401,66$ & & $8.369 .092,4$ \\
\hline$\|$ & PEKERIAAN STRUKTUR \& ARSITEKTUR & & & & & & \\
\hline$A$ & PEKERIAAN LANTAI 1 & & & & & & \\
\hline A.1. & PEKERJAAN TANAH & & & & & & \\
\hline 1 & Galian Tanah Pile Cap & 24,78 & 3 & $61.116,75$ & $1.514 .473,07$ & 2 & $1.861 .539,8$ \\
\hline 2 & Galian Tanah Sloof & 6,23 & 4 & $61.116,75$ & $380.757,35$ & 3 & $446.200,0$ \\
\hline 3 & Galian Tanah Pondasi Batu Gunung & 64,01 & 10 & $61.116,75$ & $3.912 .083,17$ & 9 & $4.181 .038,8$ \\
\hline 4 & Urugan Tanah Kembali & 23,75 & 4 & $20.368,62$ & $483.754,73$ & 3 & $566.900,0$ \\
\hline 5 & Urugan Pasir bawah Poer tebal $20 \mathrm{~cm}$ & 4,45 & 3 & $161.894,70$ & $720.431,42$ & 2 & $885.530,2$ \\
\hline 6 & Urugan Pasir bawah Sloof tebal $10 \mathrm{~cm}$ & 2,27 & 2 & $161.894,70$ & $367.500,97$ & 1 & $493.829,4$ \\
\hline 7 & $\begin{array}{l}\text { Urugan Pasir bawah Pondasi Batu Gunung } \\
\text { tebal } 20 \mathrm{Cm}\end{array}$ & 14,05 & 3 & $161.894,70$ & $2.274 .620,54$ & 2 & $2.795 .887,7$ \\
\hline 8 & Urugan pasir bawah lantai tebal $10 \mathrm{~cm}$ & 34,50 & 10 & $161.894,70$ & $5.585 .367,15$ & 9 & $5.969 .361,1$ \\
\hline 9 & Urugan Sirtu bawah lantai & 103,50 & 10 & $134.659,25$ & $13.937 .232,38$ & 9 & $14.895 .417,1$ \\
\hline \multirow[t]{2}{*}{10} & Pemadatan Menggunakan Stamper & 103,50 & 10 & $16.448,89$ & $1.702 .460,12$ & 10 & $1.702 .460,1$ \\
\hline & & & & & $30.878 .680,87$ & & $33.798 .164,5$ \\
\hline A.2. & PEKERIAAN PONDASI & & & & & & \\
\hline 1 & Lantai Kerja bawah Pile Cap & 1,11 & 4 & $1.028 .131,87$ & $1.141 .226,38$ & 4 & $1.141 .226,3$ \\
\hline 2 & Pondasi Strouss $\varnothing 30 \mathrm{~cm}-2 \mathrm{~m}+$ Bor Strous & 52,00 & 15 & $1.042 .339,50$ & $54.201 .654,00$ & 15 & $54.201 .654,0$ \\
\hline 3 & Pile Cap 120 120×30 cm (PC1) & 12,00 & 9 & $1.065 .413,80$ & $12.784 .965,60$ & 9 & $12.784 .965,6$ \\
\hline 4 & Pile Cap $60 \times 60 \times 30 \mathrm{~cm}$ (PC2) & 4,00 & 6 & $331.104,09$ & $1.324 .416,36$ & 6 & $1.324 .416,3$ \\
\hline 5 & Pasangan Batu Gunung 1:5 & 30,73 & 14 & $833.597,63$ & $25.616 .455,02$ & 14 & $25.616 .455,0$ \\
\hline \multirow[t]{2}{*}{6} & Aanstamping & 14,05 & 9 & $515.983,73$ & $7.249 .571,34$ & 8 & $7.803 .358,0$ \\
\hline & & & & & $102.318 .288,69$ & & $102.872 .075,3$ \\
\hline A.3. & PEKERAAAN BETON & & & & & & \\
\hline 1 & Lantai Kerja Bawah Sloof & 1,13 & 5 & $1.028 .131,87$ & $1.161 .799,01$ & 4 & $1.321 .535,0$ \\
\hline 2 & Rabat Beton Bawah Lantai & 17,25 & 10 & $1.028 .131,87$ & $17.735 .274,76$ & 9 & $18.954 .574,9$ \\
\hline 3 & Beton Sloof 20/40(S1) & 8,82 & 8 & $3.688 .288,07$ & $32.530 .700,78$ & 7 & $35.326 .307,8$ \\
\hline 4 & Beton Sloof 20/30 (S2) & 3,28 & 6 & $3.935 .102,67$ & $12.907 .136,76$ & 5 & $14.386 .079,5$ \\
\hline 5 & Beton Kolom 30/45 (K1) & 7,29 & 8 & $4.509 .951,84$ & $32.877 .548,91$ & 7 & $35.702 .963,2$ \\
\hline 6 & Beton Kolom 30/30 (K2) & 1,62 & 6 & $4.509 .951,84$ & 7.306.121,98 & 5 & $8.143 .281,7$ \\
\hline 7 & Beton Kolom Praktis $15 / 15 \mathrm{~cm}(\mathrm{KP})$ & 1,53 & 7 & $4.758 .963,44$ & 7.281.214,06 & 6 & $7.996 .333,3$ \\
\hline 8 & Beton Balok 30/60 (B1) & 9,29 & 10 & $4.477 .180,53$ & $41.593 .007,12$ & 9 & $44.452 .526,3$ \\
\hline 9 & Beton Balok 25/40 (B2) & 7,09 & 10 & $5.246 .633,63$ & $37.198 .632,44$ & 10 & $37.198 .632,4$ \\
\hline 10 & Beton Balok 20/40 (B3) & 5,46 & 10 & $5.767 .049,70$ & $31.488 .091,36$ & 10 & $31.488 .091,3$ \\
\hline 11 & Beton Konsol $25 / 60$ - 40 (KS1) & 4,43 & 10 & $5.213 .516,05$ & $23.095 .876,10$ & 10 & $23.095 .876,1$ \\
\hline & & & & & (6) & $77+2$ & 170770770 \\
\hline
\end{tabular}

Percepatan ini bertujuan agar penyelesaian proyek

\begin{tabular}{|c|c|c|c|c|c|c|c|}
\hline & Uraian Pekerjaan & Volume & \begin{tabular}{|c|} 
Durasi \\
Normal \\
\end{tabular} & Harga Satuan & Normal Cost & \begin{tabular}{|c|} 
Durasi \\
Percepatan \\
\end{tabular} & $\begin{array}{c}\text { Cost } \\
\text { Percepatan }\end{array}$ \\
\hline \multicolumn{8}{|c|}{\begin{tabular}{l|l}
$A .4$ & PEKERJAAN PASANGAN \& PLESTER \\
\end{tabular}} \\
\hline 1 & Pasang Dinding Bata 1:3 & 69,06 & 11 & $126.399,95$ & $8.729 .180,55$ & 10 & $9.274 .754,33$ \\
\hline 2 & Pasang Dinding Bata 1:5 & 113,55 & 11 & $121.790,75$ & $13.829 .339,66$ & 10 & $14.693 .673,39$ \\
\hline 3 & Plesteran Dinding 1:3 Tebal $15 \mathrm{~mm}$ & 85,80 & 9 & $59.777,81$ & $5.128 .935,67$ & 8 & $5.520 .729,37$ \\
\hline 4 & Plesteran Dinding 1:5 Tebal $15 \mathrm{~mm}$ & 214,62 & 10 & $57.318,65$ & $12.301 .727,59$ & 9 & $13.147,471,36$ \\
\hline 5 & Acian Beton Expose & 546,97 & 8 & $31.469,75$ & $17.213 .009,16$ & 7 & $18.692 .252,13$ \\
\hline 6 & Acian Dinding & 300,42 & 7 & $31.469,75$ & $9.454 .142,30$ & 6 & $10.382 .674,13$ \\
\hline \multirow[t]{2}{*}{7} & Tali Air & 12,90 & 6 & $15.907,15$ & $205.202,17$ & 5 & $228.714,92$ \\
\hline & \multicolumn{6}{|c|}{$66.861 .537,09$} & $71.940 .269,63$ \\
\hline \multicolumn{8}{|c|}{ A.5 PEKERJAAN LANTAl, PELAPIS DINDING \& RAILING } \\
\hline 1 & $\begin{array}{l}\text { Lantai Granite Tile 60x60 Cm } \\
\text { (FINO/MSTONE/DBS/Setara) }\end{array}$ & 319,46 & 16 & $259.287,63$ & $82.832 .024,68$ & 15 & $86.391 .213,24$ \\
\hline 2 & $\begin{array}{l}\text { Plint Lantai Granite Tile tinggi } 15 \mathrm{~cm} \\
\text { (FINO/MSTONE/DBS/setara) }\end{array}$ & 96,49 & 7 & $69.621,35$ & $6.717 .763,58$ & 7 & $6.717 .763,58$ \\
\hline 3 & $\begin{array}{l}\text { Lantai Tangga Granite Tile } 30 \times 60 \mathrm{~cm} \\
\text { (FINO/MSTONE/DBS/setara) }\end{array}$ & 18,08 & 7 & $259.287,63$ & $4.687 .920,26$ & 7 & $4.687 .920,26$ \\
\hline 4 & $\begin{array}{l}\text { Plint Lantai Tangga Granite Tile tinggi } 15 \mathrm{~cm} \\
\text { (FINO/MSTONE/DBS/setara) }\end{array}$ & 19,16 & 7 & $69.621,35$ & $1.333 .944,97$ & 7 & $1.333 .944,97$ \\
\hline 5 & $\begin{array}{l}\text { Keramik Lantai 30X30 cm, Rock Tile } \\
\text { (Selasar), (PLATINUM/MULIA/setara) }\end{array}$ & 13,63 & 7 & $203.694,33$ & $2.776 .353,65$ & 7 & $2.776 .353,65$ \\
\hline 6 & $\begin{array}{l}\text { Keramik Lantai } 30 \times 30 \mathrm{~cm} \text {, Kasar (KM/WC), } \\
\text { (PLATINUM/MULLA/setara) }\end{array}$ & 7,38 & 7 & $203.694,33$ & $1.503 .264,12$ & 7 & $1.503 .264,12$ \\
\hline 7 & $\begin{array}{l}\text { Keramik Dinding } 30 \times 30 \mathrm{~cm} \text {, Halus (KM/WC), } \\
\text { (PLATINUM/MULA/setara) }\end{array}$ & 19,66 & 7 & $226.534,48$ & $4.453 .667,78$ & 7 & $4.453 .667,78$ \\
\hline 8 & $\begin{array}{l}\text { Keramik Lantai } 30 \times 30 \mathrm{~cm} \text {, Kasar (T. Wudhu), } \\
\text { (PLATINUM/MULIA/setara) }\end{array}$ & 3,70 & 7 & $203.694,33$ & $753.669,00$ & 7 & $753.669,00$ \\
\hline 9 & $\begin{array}{l}\text { Keramik Dinding } 30 \times 30 \mathrm{~cm} \text {, Halus (T. } \\
\text { Wudhu), (PLATINUM/MULIA/setara) }\end{array}$ & 18,42 & 7 & $226.534,48$ & $4.172 .765,03$ & 7 & $4.172 .765,03$ \\
\hline 10 & $\begin{array}{l}\text { Railling Tangga Pas. Bata + Hand Rail Pipa } \\
\text { Stainless } \emptyset 2 "\end{array}$ & 20,56 & 8 & $800.000,00$ & $16.448 .000,00$ & 8 & $16.448 .000,00$ \\
\hline \multirow[t]{2}{*}{11} & $\begin{array}{l}\text { Pelapis Dinding Granite Tile } 30 \times 60 \mathrm{~cm} \text {, } \\
\text { Kasar (ROMAN/setara) }\end{array}$ & 8,74 & 7 & $416.831,88$ & $3.643 .110,59$ & 7 & $3.643 .110,59$ \\
\hline & \multicolumn{6}{|c|}{$129.322 .483,66$} & $132.881 .672,22$ \\
\hline \multicolumn{8}{|c|}{ A.6 PEKERIAAN DINDING PARTISI } \\
\hline 1 & $\begin{array}{l}\text { Dinding Partisi Kalsi }(8 \mathrm{~mm}+8 \mathrm{~mm}) 2 \text { sisi + } \\
\text { Rangka Hollow 40x60 mm }\end{array}$ & 26,16 & 7 & $292,409,21$ & $7.649 .424,93$ & 7 & $7.649 .424,93$ \\
\hline 2 & Plint Lantai Kalsi tinggi $20 \mathrm{~cm}$, tebal $8 \mathrm{~mm}$ & 18,90 & 7 & $42.500,00$ & $803.250,00$ & 7 & $803.250,00$ \\
\hline \multirow[t]{2}{*}{3} & List Kayu Oven $1 / 3 \mathrm{~cm}$ (Antara Partisi \& Kuse & 18,32 & 7 & $13.000,00$ & $238.160,00$ & 7 & $238.160,00$ \\
\hline & \multicolumn{6}{|c|}{$8.690 .834,93$} & $8.690 .834,93$ \\
\hline \multicolumn{8}{|c|}{ A.7 PEKERAAAN LANGIT-LANGIT/PLAFOND } \\
\hline 1 & Pasang Plafond Kalsi $6 \mathrm{~mm}$ + Rangka/KM/WC & 3,72 & 7 & $158.119,37$ & $588.204,04$ & 7 & $588.204,04$ \\
\hline \multirow[t]{2}{*}{2} & Pasang List Gypsum $5 \mathrm{~cm}$ & 10,92 & 7 & $27.666,59$ & $302.119,11$ & 7 & $302.119,11$ \\
\hline & \multicolumn{6}{|c|}{$890.323,15$} & $890,323,15$ \\
\hline \multicolumn{8}{|c|}{ A.8 PEKERIAAN KUSEN, PINTU, JENDELA \& KACA } \\
\hline 1 & Kusen aluminium 4" Silver & 181,39 & 10 & $112.242,63$ & $20.359 .690,66$ & 10 & $20.359 .690,66$ \\
\hline 2 & Slimar Pintu Alluminium (Silver) & 38,94 & 7 & $196.834,81$ & $7.664 .747,31$ & 7 & $7.664 .747,31$ \\
\hline 3 & Slimar Jendela/BV Alluminium (Silver) & 98,82 & 7 & $165.209,81$ & $16.326 .032,93$ & 7 & $16.326 .032,93$ \\
\hline 4 & Kaca polos $5 \mathrm{~mm}$ & 33,80 & 4 & $181.190,37$ & $6.124 .234,37$ & 4 & $6.124 .234,37$ \\
\hline 5 & Kaca polos $12 \mathrm{~mm}$ & 7,71 & 4 & $585.990,37$ & $4.517 .985,72$ & 4 & $4.517 .985,72$ \\
\hline 6 & Pintu PVC $70 \times 210 \mathrm{~cm}$ (Lengkap assesoris) & 2,00 & 4 & $700.000,00$ & $1.400 .000,00$ & 4 & $1.400 .000,00$ \\
\hline 7 & Sealent (antara kusen \& dinding) & 110,38 & 3 & $13.000,00$ & $1.434 .940,00$ & 3 & $1.434 .940,00$ \\
\hline & \multicolumn{6}{|c|}{$57.827 .630,99$} & $57.827 .630,99$ \\
\hline A.9 & PEKERIAAN PENGGANTUNG \& PENGUNCI & & & & & & \\
\hline 1 & Handle pintu alluminium & 4,00 & 1 & $2.233 .999,20$ & $8.935 .996,80$ & 1 & $8.935 .996,80$ \\
\hline 2 & Handle + Kunci tanam 2x putar & 4,00 & 1 & $267.499,20$ & $1.069 .996,80$ & 1 & $1.069 .996,80$ \\
\hline 3 & Engsel Pintu (Stainless Steel) & 21,00 & 2 & $68.484,92$ & $1.438 .183,22$ & 2 & $1.438 .183,22$ \\
\hline 4 & Casement Jendela/BV & 64,00 & 2 & $154.734,92$ & $9.903 .034,56$ & 2 & $9.903 .034,56$ \\
\hline 5 & Grendel jendela/BV & 32,00 & 1 & $69.634,92$ & $2.228 .317,28$ & 1 & $2.228 .317,28$ \\
\hline 6 & Grendel Tanam & 4,00 & 2 & $194.984,92$ & $779.939,66$ & 2 & $779.939,66$ \\
\hline 7 & Floor Hinge & 8,00 & 1 & $2.233 .999,20$ & $17.871 .993,60$ & 1 & $17.871 .993,60$ \\
\hline & & & & & $42.227 .461,92$ & & $42.227 .461,92$ \\
\hline
\end{tabular}
dapat sesuai denganjawal yang telah direncanakan yaitu pada minggu ke 20, pada proyek pembangunan Gedung Kantor Dinas Perdagangan dan Perindustrian biaya langsung yang dikeluarkan adalah Rp. 1.227.823.795 dengan durasi 741 hari untuk menyelesaikan pekerjaan struktur. Untuk estimasibiaya tidak langsung digunakan asumsi sebesar 5\% dari biaya langsung proyek.

Tabel 4.2. Perhitungan Cost Normal Dan Cost Percepatan (Microsoft Project) 
Jurnal Rekayasa Tenik Sipil Universitas Madura Vol. 4 No.2 Desember 2019 ISSN 2527-5542

\begin{tabular}{|c|c|c|c|c|c|c|c|}
\hline & Uraian Pekerjaan & Volume & \begin{tabular}{|l} 
Durasi \\
Normal \\
\end{tabular} & Harga Satuan & Normal Cost & $\begin{array}{c}\text { Durasi } \\
\text { Percepatan }\end{array}$ & $\begin{array}{c}\text { Cost } \\
\text { Percepatan }\end{array}$ \\
\hline A.10 & 0 PEKERJAAN SANITAIR & & & & & & \\
\hline 1 & Kloset Duduk + Tabung & 2,00 & 2 & $3.851 .331,26$ & $7.702 .662,51$ & 2 & $7.702 .662,51$ \\
\hline 2 & Kran Air & 4,00 & 2 & $299.319,70$ & $1.197 .278,80$ & 2 & $1.197 .278,80$ \\
\hline 3 & Jet Spray Closed & 1,00 & 2 & $448.819,70$ & $448.819,70$ & 2 & $448.819,70$ \\
\hline 4 & Floor Drain Stainless & 4,00 & 2 & $310.647,20$ & $1.242 .588,80$ & 2 & $1.242 .588,80$ \\
\hline \multirow[t]{2}{*}{5} & Tempat Sabun Keramik & 2,00 & 2 & $120.000,00$ & $240.000,00$ & 2 & $240.000,00$ \\
\hline & \multicolumn{6}{|c|}{$10.831 .349,81$} & $10.831 .349,81$ \\
\hline A.11 & 1 PEKERJAAN PENGECATAN & & & & & & \\
\hline 1 & Cat Dinding \& Beton & 847,39 & 14 & $50.181,99$ & $42.523 .716,51$ & 14 & 42.523.716,51 \\
\hline 2 & Cat Partisi & 52,32 & 7 & $50.181,99$ & $2.625 .521,72$ & 7 & $2.625 .521,72$ \\
\hline 3 & Cat Plafond & 37,80 & 7 & $50.181,99$ & $1.896 .879,22$ & 7 & $1.896 .879,22$ \\
\hline 4 & Cat Plint Partisi (Cat kayu/besi) & 3,78 & 7 & $34.800,00$ & $131.544,00$ & 7 & $131.544,00$ \\
\hline \multirow[t]{2}{*}{5} & Cat List Partisi Kayu Oven (Cat kayu/besi) & 0,92 & 7 & $34.800,00$ & $32.016,00$ & 7 & $32.016,00$ \\
\hline & \multicolumn{6}{|c|}{$47.209 .677,44$} & $47.209 .677,44$ \\
\hline A.12 & PEKERJAAN ATAP & & & & & & \\
\hline 1 & Atap Penutup Tangga & 12,35 & 6 & $8000.000,00$ & $9.880 .000,00$ & 5 & $11,012.083,33$ \\
\hline \multirow[t]{2}{*}{2} & Atap Selasar/Kanopi & 10,63 & 7 & $800.000,00$ & $8.504 .000,00$ & 6 & $9.339 .214,29$ \\
\hline & & & & & $18.384 .000,00$ & & $20.351 .297,62$ \\
\hline III & PEKERAAN MEKANIKAL EEEKTRIKAL & & & & & & \\
\hline $\mathrm{A}$ & PEKERJAAN ELEKTRIKAL & & & & & & \\
\hline a & Panel & & & & & & \\
\hline \multirow[t]{2}{*}{1} & Panel Penerangan LP-1 & 1,00 & 2 & $5.000 .000,00$ & $5.000 .000,00$ & 1 & $6.718 .750,00$ \\
\hline & & & & & $5.000 .000,00$ & & $6.718 .750,00$ \\
\hline$b$ & Instalasi Penerangan \& Stop Kontak & & & & & & \\
\hline 1 & Lampu LED 18 Watt + Fitting & 18,00 & 2 & $178.163,75$ & $3.206 .947,50$ & 1 & $4.309 .335,70$ \\
\hline 2 & Lampu LED 9 Watt + Fitting & 5,00 & 2 & $120.663,75$ & $603.318,75$ & 1 & $810.709,57$ \\
\hline 3 & Lampu LED 4 Watt + Fitting & 4,00 & 2 & $80.413,75$ & $321.655,00$ & 1 & $432.223,91$ \\
\hline 4 & Stop Kontak 200 W $1 \mathrm{P}$ & 7,00 & 2 & $58.563,75$ & $409.946,25$ & 1 & $550.865,27$ \\
\hline 5 & Saklar Tunggal & 3,00 & 2 & $56.263,75$ & $168.791,25$ & 2 & $168.791,25$ \\
\hline 6 & Saklar Ganda & 8,00 & 2 & $58.563,75$ & $468.510,00$ & 2 & $468.510,00$ \\
\hline 7 & Instalasi Penerangan & 27,00 & 2 & $211.487,30$ & $5.710 .157,10$ & 2 & $5.710 .157,10$ \\
\hline \multirow[t]{2}{*}{8} & Instalasi Stop Kontak & 7,00 & 2 & $298.887,30$ & $2.092 .211,10$ & 2 & $2.092 .211,10$ \\
\hline & \multicolumn{6}{|c|}{$12.981 .536,95$} & $14.542 .803,90$ \\
\hline \multirow{5}{*}{ a } & Pekerjaan AC & & & & & & \\
\hline & $\begin{array}{l}\text { - ACSplit1PK Wall Mounted (ex. } \\
\text { Panasonic/Samsung) }\end{array}$ & 1,00 & 2 & $5.500 .000,00$ & $5.500 .000,00$ & 2 & $5.500 .000,00$ \\
\hline & $\begin{array}{l}\text { - Instalasi Pipa Refigerant, Pipa drain \& } \\
\text { Kabel Kontrol (Split Wall Mounted) }\end{array}$ & 1,00 & 2 & $500.000,00$ & $500.000,00$ & 2 & $500.000,00$ \\
\hline & -Stop Kontak $1000 \mathrm{~W}$ & 1,00 & 2 & $90.000,00$ & $90.000,00$ & 2 & $90.000,00$ \\
\hline & $\begin{array}{l}\text { - Instalasi Stop Kontak } 1000 \text { W (AC) NYM } \\
3 \times 2,5 \mathrm{~mm}^{2}+\text { conduit }\end{array}$ & 1,00 & 2 & $360.987,30$ & $360.987,30$ & 2 & $360.987,30$ \\
\hline & & & & & & & \\
\hline$b$ & $\begin{array}{l}\text { - ACSplit 1,5 PK Wall Mounted (ex. } \\
\text { Panasonic/Samsung) }\end{array}$ & 4,00 & 2 & $8.350 .000,00$ & $33.400 .000,00$ & 2 & $33.400 .000,00$ \\
\hline & $\begin{array}{l}\text { - Instalasi Pipa Refigerant, Pipa drain \& } \\
\text { Kabel Kontrol (Split Wall Mounted) }\end{array}$ & 4,00 & 2 & $500.000,00$ & $2.000 .000,00$ & 2 & $2.000 .000,00$ \\
\hline & -Stop Kontak $1000 \mathrm{~W}$ & 4,00 & 2 & $90.000,00$ & $360.000,00$ & 2 & $360.000,00$ \\
\hline & $\begin{array}{l}\text { - Instalasi Stop Kontak } 1000 \text { W (AC) NYM } \\
3 \times 2,5 \mathrm{~mm}^{2}+\text { conduit }\end{array}$ & 4,00 & 2 & $360.987,30$ & $1.443 .949,20$ & 2 & $1.443 .949,20$ \\
\hline & & & & & $43.654 .936,50$ & & $43.654 .936,50$ \\
\hline$c$ & Pekerjaan Plumbing & & & & & & \\
\hline \multirow{5}{*}{$\begin{array}{l}\mathrm{a} \\
\\
\end{array}$} & Instalasi Air Bersih & & & & & & \\
\hline & - Pipa PVC AW $\emptyset 3 / 4^{1}$ & 30,00 & 5 & $16.500,00$ & $495.000,00$ & 4 & $563.062,50$ \\
\hline & - Gate Valve $\emptyset 3 / 4 "$ ex. ONDA/TOYO & 2,00 & 2 & $230.000,00$ & $460.000,00$ & 1 & $618.125,00$ \\
\hline & - Material Bantu & 1,00 & 1 & $200.000,00$ & $200.000,00$ & 1 & $200.000,00$ \\
\hline & & & & & $1.155 .000,00$ & & $1.381 .187,50$ \\
\hline$b$ & Instalasi Air Kotor \& Kotoran & & & & & & \\
\hline & - Pipa PVC AW Dia. 4" & 12,00 & 5 & $110.000,00$ & $1.320 .000,00$ & 4 & $1.501 .500,00$ \\
\hline & - Pipa PVC AW Dia. 2,5" & 20,00 & 2 & $62.500,00$ & $1.250 .000,00$ & 1 & $1.679 .687,50$ \\
\hline & - Material Bantu & 1,00 & 1 & $225.000,00$ & $225.000,00$ & 1 & $225.000,00$ \\
\hline & & & & & $2.795 .000,00$ & & $3.406 .187,50$ \\
\hline$c$ & Septitank \& Resapan & & & & & & \\
\hline & $\begin{array}{l}\text { Septitank Biofil } 1 \mathrm{~m} 3 \text { (Include galian }+ \\
\text { Penutup beton) }\end{array}$ & 1,00 & 7 & $6.250 .000,00$ & $6.250 .000,00$ & 6 & $6.863 .839,29$ \\
\hline & Resapan & 1,00 & 5 & $1.800 .000,00$ & $1.800 .000,00$ & 4 & $2.047 .500,00$ \\
\hline & & & & & $8.050 .000,00$ & & $8.911 .339,29$ \\
\hline
\end{tabular}

\begin{tabular}{|c|c|c|c|c|c|c|c|}
\hline & Uraian Pekerjaan & Volume & $\begin{array}{l}\text { Durasi } \\
\text { Normal }\end{array}$ & Harga Satuan & Normal Cost & $\begin{array}{c}\text { Durasi } \\
\text { Percepatan } \\
\end{array}$ & $\begin{array}{c}\text { Cost } \\
\text { Percepatan }\end{array}$ \\
\hline \multicolumn{8}{|c|}{\begin{tabular}{l|l}
$D$ & Pekerjaan saluran Drainase \\
\end{tabular}} \\
\hline & Saluran Tertutup & 10,00 & 7 & $900.000,00$ & $9.000 .000,00$ & 6 & $9.883 .928,57$ \\
\hline & Saluran Terbuka & 10,00 & 7 & $382,333,93$ & $3.823 .339,30$ & 6 & $4.198 .845,84$ \\
\hline & Saluran PVCAW $66^{\prime \prime}$ & 10,00 & 7 & $210.000,00$ & $2.100 .000,00$ & 6 & $2.306 .250,00$ \\
\hline & Bak Kontrol Terbuka & 2,00 & 7 & $443.522,98$ & $887.045,96$ & 7 & $887.045,96$ \\
\hline & Bak Kontrol Tetutup & 2,00 & 7 & $946.991,41$ & $1.893 .982,82$ & 7 & $1.893 .982,82$ \\
\hline & $\begin{array}{l}\text { Bak Kontrol Tertutup + Drainage Control } \\
\text { Cover }\end{array}$ & 2,00 & 7 & $1.146 .992,85$ & $2.293 .985,70$ & 7 & $2.293 .985,70$ \\
\hline \multicolumn{7}{|c|}{$19.998 .353,78$} & $21.464,038,89$ \\
\hline \multicolumn{8}{|c|}{ E Pekerjaan Paving } \\
\hline & Urugan Sirtu & 68,40 & 8 & $134,659,25$ & $9.210 .692,70$ & 7 & $10,002,236,00$ \\
\hline & Pemadatan Menggunakan Stamper & 68,40 & 8 & $16.448,89$ & $1.125 .104,08$ & 7 & $1.221,792,71$ \\
\hline & Paving Block Tebal $6 \mathrm{~cm}$ K-300 & 360,00 & 18 & $136.606,17$ & $49.178 .221,65$ & 17 & $51.056 .556,50$ \\
\hline \multirow{2}{*}{\multicolumn{2}{|c|}{ Kanstin Beton K-300 }} & 69,40 & 6 & $124.422,23$ & $8.634,902,48$ & 5 & $9.624 .318,39$ \\
\hline & & & & & $68.148 .920,91$ & & $71,904,904,21$ \\
\hline & TOTAL & & 741 & & 1.227 .823 .795 & 693 & 1.256.929.349 \\
\hline
\end{tabular}

Sumber : ( Microsoft Project)

Dari Tabel 4.2. diatas didapat 48 pekerjaan proyek yang dipercepat diperoleh :

a. Hasil Kalkulasi Seluruh Pekerjaan( Microsoft Project ):

1. Durasi penyelesaian : 150 hari

Total biaya penyelesaian : Rp. 1.227.823.795

2. Durasi setelah dipercepat : 133 hari

Total biaya percepatan : Rp. 1.256.929.349

3. Durasi percepatan : Durasi penyelesaian - Durasi percepatan

$$
: 150-133
$$

: 17 hari

4. Biaya percepatan : Biaya percepatan - Biaya penyelesaian

$$
\text { :Rp. 1.256.929.349 - Rp. 1.227.823.795 }
$$

: Rp. 29.105.553

$$
\begin{aligned}
& =\text { Rp. } 29.105 .553=\operatorname{Rp} 1.227 .823 .795 \times \frac{\mathrm{x}}{100} \\
& =\frac{\operatorname{Rp} 29.105 .553}{\operatorname{Rp} 1.227 .823 .795} \\
& =2.37 \%
\end{aligned}
$$

5. Biaya tak langsung waktu penyelesaian : 5\% x Biaya penyelesaian

:5\% x Rp. 1.227 .823 .795

: Rp. 61.391.189,76

6. Biaya tak langsung waktu penyelesain perhari :

: Biaya tak langsung waktu penyelesaian

$$
: \frac{61.391 .189,76}{741}
$$

: Rp.82.849.109

7. Biaya tak langsung waktu dipercepat yang dipercepat

: $5 \%$ x Biaya total proyek

: $5 \%$ x Rp. 1.256.929.349

: Rp. 62.846.467,4

8. Biaya tak langsung waktu dipercepat perhari :

$$
\begin{aligned}
& : \frac{\text { Biaya tak langsung waktu penyelesaian }}{\text { Durasi Penyelesaian }} \\
& : \frac{62.846 .467,76}{693}
\end{aligned}
$$

: Rp 90.687.543,7 


\section{KESIMPULAN}

Berdasarkan hasil analisa yang telah dilakukan dalam Tugas Akhir ini, dihasilkan kesimpulan yaitu sebagai berikut:

1. Dari hasil penjadwalan ulang pembangunan Gedung Kantor Dinas Perdagangan dan Perindustrian dengan menerapkan metode ( Time Cost Trade Off ) didapat waktu penyelesaian akibat percepatan adalah 133 hari dari durasi penyelesaian sebesar 150 hari jadi diperlukan percepatan 17 hari agar proyek dapat selesai sesuai target rencana.

2. Biaya total akibat pecepatan sebesar Rp. 1.256.929.349 dari biaya sebelumnya Rp. 1.227.823.795 terjadi penambahan biaya sebesar Rp. 29.105.553 Sehinnga didapat $2.37 \%$ kenaikan anggran.

\section{SARAN}

1. Diharapkan untuk peneliti selanjutnya dapat mengembangkan penelitian tentang Analisa Time Cost Trade Off, misalnya dengan mengembangkan analisa dengan menambahkan pekerjaan arsitektur.

2. Perhitungan yang dilakukan akan lebih bermanfaat apabila dipakai kontraktor menengah kebawah yang menangani beberapa proyek lebih dari dua proyek.

\section{DAFTAR PUSTAKA}

Febriyannor, R. 2016. Analisis Percepatan Pelaksanaan Pembagunan Rusunawa Dengan menambah Jam Kerja dan Tenaga Kerja Menggunakan Tracking MS. Project. Skripsi. Program Pascasarjana Universitas Brawijaya. Malang

Kisworo, R.W. et al. 2017. Analisis Percepatan Proyek Menggunakan Metode Time Cost Trade Off Dengan Penambahan Jam Kerja Lembur dan Jumlah Alat. E-jurnal Matriks Teknik Sipil/ September 2017/766

Kustiani, I. Et al. 2016. Analiis Time Cost Trade Off Untuk Mengejar Keterlambatan Pelaksanaan Proyek Di Bandar Lampung. Jurnal Rekayasa, Vol. 20, No. 2, Agustus 2016

Mela, A.F. 2016. analisis time cost trade off untuk mengejar keterlambatan pelaksanaan proyek Study kasus: pembangunan hotel Zodiak Lampung, Pembangunan hotel park in by radisson, pembangunan toko Mitra hasil sentosa di bandar lampung. Skripsi. Program Pascasarjana Universitas Lampung. Bandar Lampung

Priyo, M. dan A. Sumanto. 2016. Analisis Percepatan Waktu dan Biaya Proyek Konstruksi Dengan Penambahan Jam Kerja (Lembur) Menggunakan Metode Time Cost Trade Off: Study Kasus Proyek Pembangunan Prasarana Pengendali
Banjir. Jurnal Ilmiah Semesta Teknika Vol 19, No. 1, 1-15, Mei 2016

Simatupang, J.S. et al. 2015. Pengaruh percepatan durasi terhadap waktu pada proyek konstruksi (study kasus: Pembangunan persekolahan Eben Haezar Manado). Jurnal Sipil Statik Vol. 3 No. 5 Mei 2015 (281-280) ISSN: 2337-6732

Taufik, H. dan Jurandi. 2017. Analisis Percepatan Terhadap Biaya Proyek (Study Kasus: Kantor Dinas SKPD Gedung B5 Tenayan Raya). Jom FTEKNIK Volume 4 No. 2 Oktober 2017 